\title{
Relationship between Polynomial Geometric Surfaces Terms and Observation Points Numbers and Effect in the Accuracy of Geometric Geoid Models
}

\author{
Eteje, S. O.*, Oduyebo, O. F., Oluyori, P. D. \\ Department of Surveying and Geoinformatics, Nnamdi Azikiwe University, Awka, Nigeria \\ Corresponding Author: eteje.sylvester@yahoo.com
}

\begin{abstract}
The application of the geometric method of local geoid model determination which requires the fitting of geometric surfaces to known geoid heights to enable geoid heights of new points to be interpolated involves the use of least squares technique for computation of the models' parameters. The selection of polynomial geometric surfaces depends on the size of the study area, the variation of the geoid heights and the number of measurement points. The accuracy of the geometric geoid model increases as the number of observation points approximates the number of geometric surface terms. But in most cases, the number of observation points is not considered. To this effect, this paper presents the relationship between geometric surfaces terms and observation points numbers and effect in the accuracy of geometric geoid models. A total of 23 points of known local gravimetric geoid heights were used. Two polynomial geometric (third and fifth degrees) surfaces were fitted to the geoid heights at various observation point numbers and compared to determine the relationship between the number of model terms and that of observation points and effect in the accuracy of the models. Least squares adjustment technique was applied to obtain the model parameters. The differences between the models and the known geoid heights of the points were computed and used to obtain the RMSEs as well as the accuracy of the models. The obtained results showed that the accuracy of the polynomial geometric geoid models tends to the highest as the number of measurement points approximates the number of the model terms and in a unique solution where the number of observation points is equal to the number of the polynomial geometric model terms, the model accuracy is highest. The paper recommends that the geometric method of local geoid model determination should be strictly applied in small areas. Where the method will be applied in considerable large areas, higher degrees polynomial geometric surfaces with a larger number of terms approximating the number of observation points should be applied. This will enable a proper fit of the polynomial surface to the known geoid heights, as well as high accuracy to be obtained.
\end{abstract}

Keywords-accuracy, geometric geoid, model terms, points number, polynomial surfaces.

\section{INTRODUCTION}

The transformation of GNSS ellipsoidal heights to practical, orthometric heights in local areas has necessitated the determination of local geoid models of various areas. Local geoid model is determined using several methods such as gravimetric, gravimetricgeometric, astro-geodetic and geometric methods. The gravimetric method involves the use of either free air or Bouguer gravity anomalies computed from absolute gravity values of selected points obtained with a gravimeter within the study area and theoretical gravity obtained on the local ellipsoid adopted for geodetic computation in the study area as given by Eteje et al.
(2019). The gravimetric-geometric method uses the geoid heights of points obtained from gravity observation and a geometric surface fitted to the gravimetric geoid heights to enable geoid heights of new points to be interpolated within the study area. The astro-geodetic method has to do with the use of astronomically and geodetically obtained data. The geometric method is applied in a small area and requires the use of levelling and GNSS acquired data such as orthometric and ellipsoidal heights of points accurately obtained with respect to reliable benchmarks and geodetic controls. Using the orthometric and ellipsoidal heights of the points, the geoid heights of the 
points are computed (see figure 1) with (Oluyori et al. 2018)

$$
N=h-H
$$

Where,

$$
\begin{aligned}
& \mathrm{N}=\text { Geoid height } \\
& \mathrm{h}=\text { Ellipsoidal height } \\
& \mathrm{H}=\text { Orthometric height }
\end{aligned}
$$

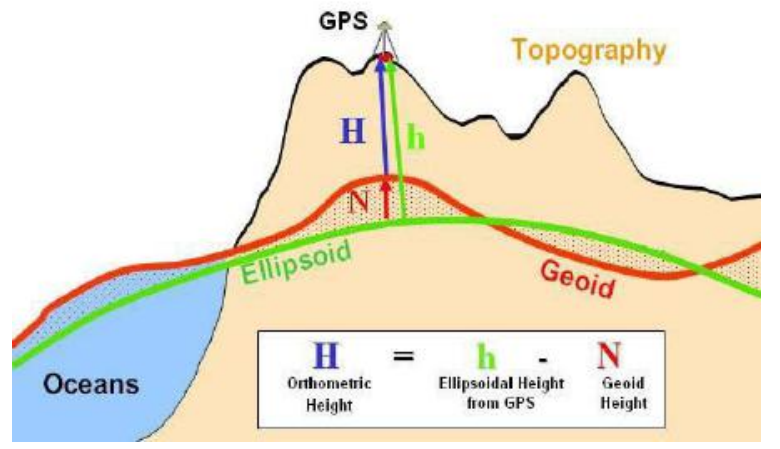

Fig. 1: Relationship between Orthometric, Geoid and Ellipsoidal Heights

Source: Eteje et al. (2018)

The geometric method has been applied by various researchers in different parts of the world. Such researchers include Erol and Celik (2004) which applied the fifth-degree geometric surface in an area of $50 \times 45 \mathrm{~km}^{2}$ in Turkey and Oluyori et al. (2018) that also applied the second-degree and the third-degree surfaces in the Federal Capital Territory, FCT, Abuja, Nigeria among others.

Applying the geometric method for the determination of a local geoid model of an area, the geoid heights of selected points are normally computed from the orthometric and ellipsoidal heights of the points and a geometric geoid surface is fitted to the obtained geoid heights of the points to enable geoid heights of new points to be interpolated using the model. The selection of a method simply depends on the size of the study area, the variation of the geoid heights and the total number of points. Usually, two or more geometric surfaces are fitted to the geoid heights and their accuracy are computed and compared. The model with the highest accuracy, best fit the points as well as the study area and it is recommended for application in the study area.

The fitting of the geometric surface to the geoid heights of chosen points in the study area requires the computation of the model parameters which in turn requires the application of least squares technique. In most cases, the lager the study area, the larger the number of points to be used for the determination of the geoid model. This enables proper depicting of the shape of the geoid model.

It is assumed that the computed geoid heights have been adjusted. The application of the least-squares technique here is to obtain the model parameters. It is to be noted here that the reliability of the model depends on its ability to reproduce accurately the known geoid heights of the points.

The accuracy with which geoid heights are obtained using the determined geoid model is computed by finding the differences between the known geoid heights of the points and their respective geoid heights from the model (model geoid heights). The differences are used to compute the Root Mean Square Error, RMSE as well as the reliability of the model. The accuracy of the model is usually highest when applying the least squares technique for the computation of the model parameters as well as fitting the geometric surface to the geoid heights of the points when the number of the chosen points is equal to the number of the model terms. In other words, in a unique solution where the number of observations is equal to the number of unknown parameters. Using the least squares technique, the differences between the estimates (most probable values) and observations is the residual and this is equal to the differences between the model and the known geoid heights of the points.

Considering the fact that the highest accuracy of the geometric geoid model is obtained when the number of points is equal to the number of geometric surface terms, then when applying the method in a very large area which in turn requires large number of points, a geometric surface with a large number of terms should be applied. It is also to be noted here that, the higher the degree of the model, the larger the number of the model terms. But often time, the geometric surfaces are chosen considering the size of the study area and the variation of the geoid heights only. To this effect, this paper presents the relationship between geometric surfaces terms and observation points numbers and effect in the accuracy of geometric geoid models.

\subsection{Geometric Geoid Surfaces}

Geometric geoid surfaces are mathematical interpolation surfaces fitted to geoid heights to enable geoid heights of new points to be interpolated using variables such as geographic or rectangular coordinates of the points. These surfaces include plane surface, bi-linear surface, second-degree surface, third-degree polynomial and fifth-degree polynomial (Eteje et al., 2018). The surface to be adopted as well as the degree and order of the polynomial depending on the size of the study area, 
the variation of the geoid heights and the number of observation points.

\subsubsection{Polynomial Surface}

The polynomial surface used when determining geoid model is given by Erol and Celik (2004) and Kirici and Sisman (2017) as

$$
N_{(x, y)}=\sum_{i=0}^{m} \sum_{\substack{j=k-i \\ i=0}}^{k} a_{i j} x^{i} y^{j}
$$

Where,

$$
\begin{aligned}
& a_{i j}=\text { polynomial coefficients } \\
& m=\text { degree of polynomial } \\
& x, y=\text { plan coordinates of point }
\end{aligned}
$$

In applying the polynomial, the degree should be chosen and the polynomial should be formed for the chosen degree. Kirici and Sisman (2017) gave the third-degree polynomial surface with 10 terms as

$$
\begin{aligned}
N= & a_{0}+a_{1} X+a_{2} Y+a_{3} X Y+a_{4} X^{2}+ \\
& a_{5} Y^{2}+a_{6} X^{2} Y+a_{7} X Y^{2}+a_{8} X^{3}+ \\
& a_{9} Y^{3}
\end{aligned}
$$

The fifth-degree polynomial geometric geoid surface with 21 terms is also given as

$$
\begin{aligned}
N= & a_{0}+a_{1} X+a_{2} Y+a_{3} X Y+a_{4} X^{2}+ \\
& a_{5} Y^{2}+a_{6} X^{2} Y^{2}+a_{7} X^{2} Y+a_{8} X Y^{2}+ \\
& a_{9} X^{3}+a_{10} Y^{3}+a_{11} X^{3} Y+a_{12} X^{3} Y^{2}+ \\
& a_{13} X^{2} Y^{3}+a_{14} X Y^{3}+a_{15} X^{4}+a_{16} Y^{4}+ \\
& a_{17} X^{4} Y+a_{18} X Y^{4}+a_{19} X^{5}+a_{20} Y^{5}
\end{aligned}
$$

Where,

$$
\begin{aligned}
& Y=A B S\left(y-y_{o}\right) \\
& X=A B S\left(x-x_{o}\right) \\
& y=\text { Northing coordinate of observed station } \\
& x=\text { Easting coordinate of observed station } \\
& y_{o}=\text { Northing coordinate of the origin (average } \\
& \quad \text { of the northing coordinates) } \\
& x_{o}=\text { Easting coordinate of the origin (average of } \\
& \quad \text { the easting coordinates) }
\end{aligned}
$$

\subsection{Observation Equation Method of Least Squares} Adjustment

The fitting of geometric geoid surface to a set of geoid heights requires the model parameters to be computed. The computation of these parameters is done by observation equation method of least squares adjustment technique. The functional relationship between adjusted observations and the adjusted parameters as given by Ono et al. (2014) is:

$L_{a}=F\left(X_{a}\right)$

Where, $L_{a}=$ adjusted observations and $X_{a}=$ adjusted parameters. Equation (5) is a linear function and the general observation equation model was obtained. The system of observation equations is presented by matrix notation as (Mishima and Endo, 2002 and Ono et al., 2018):

$V=A X-L$

where,

$$
\begin{aligned}
& A=\text { Design/Coefficient Matrix, } \\
& X=\text { Vector of Unknowns } \\
& L=\text { Observation Matrix. } \\
& V=\text { Residual }
\end{aligned}
$$

The residual, $V$ which is the difference between the estimate and the observation is usually useful when applying least squares adjustment technique for determination of local geometric geoid model parameters. Since it is equal to the difference between the model geoid heights and the known geoid heights of the points. So, it can be used as a check.

The unknown parameter is computed as

$$
X=\left(A^{T} A\right)^{-1} A^{T} L
$$

where,

$$
\left(A^{T} A\right)^{-1}=\text { Inverse of the normal matrix }
$$

The step by step procedures for the computation of geometric geoid model parameters are detailed in Eteje and Oduyebo (2018).

\subsubsection{Accuracy of Geometric Geoid Model}

The accuracy of a local geometric geoid model is obtained using the Root Mean Square Error, RMSE index. To evaluate the local geometric geoid model accuracy, the geoid heights of the points from the model are compared with their corresponding known geoid heights (geoid heights of the points to which the geometric surface was fitted) to obtain the residuals. The residual and the total number of selected points are used for the computation of the RMSE, as well as the accuracy of the geometric geoid model. The Root Mean Square Error, RMSE index for the computation of the geometric geoid model accuracy as given by Kao et al. (2017), and Eteje and Oduyebo (2018) is

$$
R M S E= \pm \sqrt{\frac{V^{T} V}{n}}
$$

Where,

$$
V=N_{\text {Model }}-N_{\text {Known }}(\text { Residual })
$$




$$
\begin{aligned}
& N_{\text {Model }}=\text { Model Geoid Height of Point } \\
& N_{\text {Known }}=\text { Known Geoid Height of Point } \\
& \mathrm{n}=\text { Number of Points }
\end{aligned}
$$

\section{METHODOLOGY}

The adopted methodology was divided into different stages such as data acquisition, data processing, and results presentation and analysis. Figure 2 shows the adopted methodology flow chart.

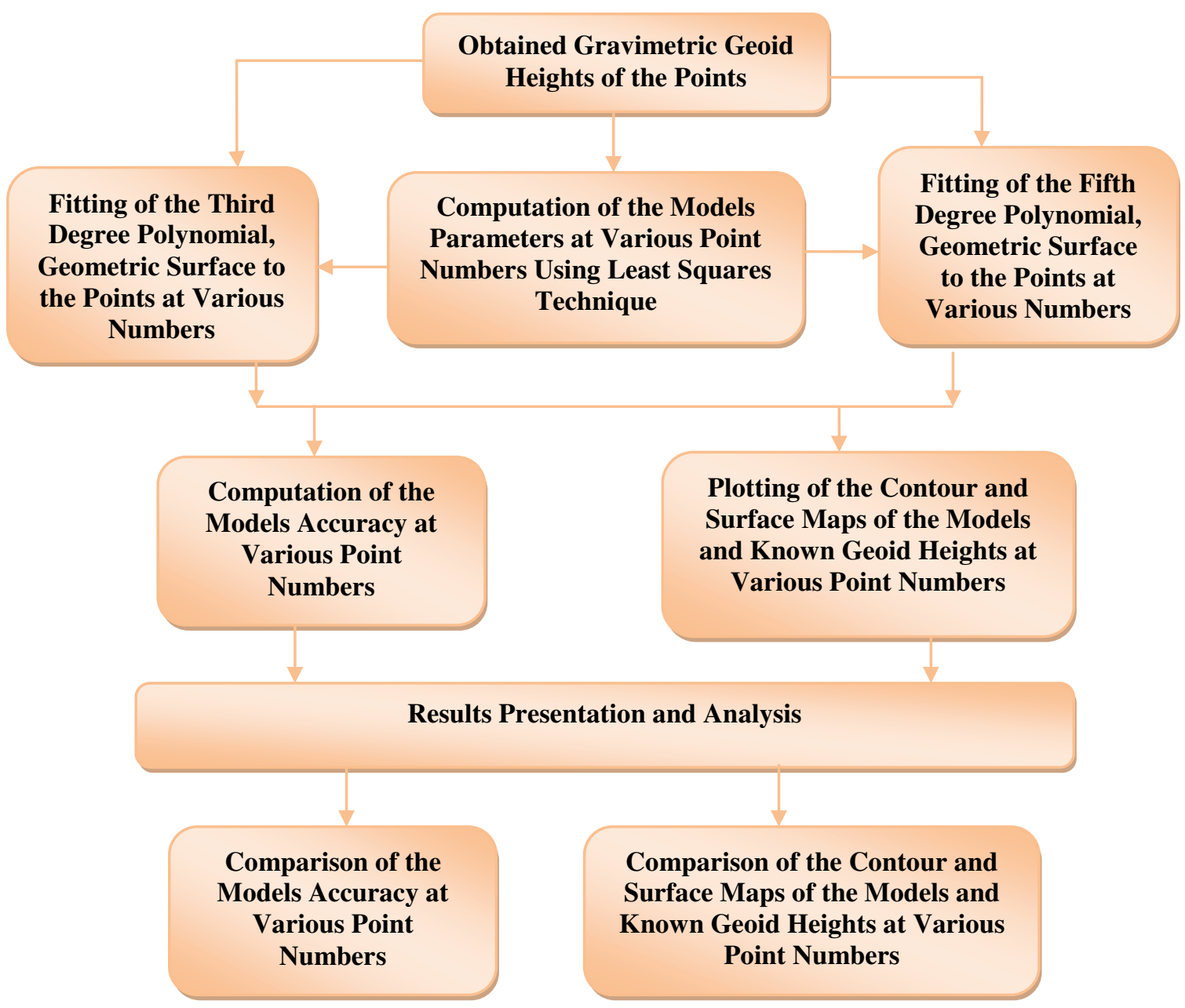

Fig. 2: Adopted Methodology Flow Chart

The geoid heights used in this study were obtained by gravimetric means. They were part of the local gravimetric geoid heights obtained for the determination of the local geoid model of Benin City. The geoid heights were computed using the integration of modified Stokes' integral given by Featherstone and Olliver (1997). They were also corrected for combined topographic effect. A total of 23 local gravimetric geoid heights were used. Table 1 shows the 23 local gravimetric geoid heights used in this study.

Table 1: Local Gravimetric Geoid Heights of the Points

\begin{tabular}{|c|c|c|c|}
\hline STASTION & Northing & Easting & $\begin{array}{c}\text { Free Air Geoid Height, N Corrected } \\
\text { for Combined Topographic Effect }\end{array}$ \\
\hline XSU92 & 257998.9800 & 357763.3720 & 2.086 \\
\hline RR01 & 257885.3227 & 355124.0166 & 2.420 \\
\hline SR02 & 253034.8393 & 356093.6672 & 1.978 \\
\hline SR05 & 245976.7564 & 356615.1406 & 2.802 \\
\hline SR06 & 244918.0916 & 356628.3396 & 3.266 \\
\hline UU02 & 265145.3515 & 353468.5482 & 3.498 \\
\hline
\end{tabular}




\begin{tabular}{|c|c|c|c|}
\hline UU03 & 262403.8368 & 354173.5295 & 1.981 \\
\hline UU05 & 259407.1043 & 355613.0973 & 1.346 \\
\hline UU08 & 256422.9868 & 355521.4167 & 1.263 \\
\hline AD01 & 260514.8753 & 359958.1194 & 2.986 \\
\hline AD03 & 261867.2294 & 361745.9231 & 4.420 \\
\hline AK02 & 259528.7811 & 356853.3277 & 1.473 \\
\hline AK05 & 259332.1257 & 362604.6963 & 3.954 \\
\hline MR02 & 260751.5081 & 356528.1658 & 1.488 \\
\hline MR04 & 262930.8267 & 360077.3193 & 4.037 \\
\hline MR05 & 262428.2213 & 361076.8116 & 4.313 \\
\hline SK02 & 255516.1557 & 357459.1723 & 2.035 \\
\hline SK03 & 254396.4836 & 358439.3812 & 2.379 \\
\hline SLK01 & 259894.0672 & 352909.3470 & 0.781 \\
\hline SLK03 & 261813.3387 & 350594.2641 & 1.736 \\
\hline SLK05 & 264774.9356 & 348869.1903 & 3.357 \\
\hline EK02 & 257209.3523 & 350068.7731 & 0.983 \\
\hline EK05 & 252877.2407 & 345740.0760 & 2.516 \\
\hline
\end{tabular}

\subsection{Data Processing}

The two polynomial geometric surfaces were fitted to the geoid heights at various point numbers. Considering the third-degree with 10 terms polynomial surface given in equation (3), 23 points, 22 points except for point SLK01, 21 points except for points SLK01 and UU03, and 11 points (XSU92, RR01, SR06, UU02,

Degree 3 with 10 terms (23 Points)

$$
\left(\begin{array}{l}
a_{0} \\
a_{1} \\
a_{2} \\
a_{3} \\
a_{4} \\
a_{5} \\
a_{6} \\
a_{7} \\
a_{8} \\
a_{9}
\end{array}\right)=\left(\begin{array}{c}
3.11075532680599771371 \\
-0.00120394557065107907 \\
-0.00108658105231516264 \\
0.00000016658414901717 \\
0.00000056608595962784 \\
0.00000017705155729573 \\
-0.00000000000104326161 \\
-0.00000000004438844605 \\
-0.00000000003086059461 \\
-0.00000000000746460180
\end{array}\right)
$$

UU08, AD03, AK05, MR05, SK03, SLK05 and EK05) given in table 1 were used. The model parameters of the various point numbers using the third-degree polynomial surface were computed with least squares technique as well as equation (6). The computed model parameters for 23, 22, 21 and 11 points using the third-degree polynomial surface are respectively

Degree 3 with 10 terms (22 Points)

$$
\left(\begin{array}{l}
a_{0} \\
a_{1} \\
a_{2} \\
a_{3} \\
a_{4} \\
a_{5} \\
a_{6} \\
a_{7} \\
a_{8} \\
a_{9}
\end{array}\right)=\left(\begin{array}{c}
2.73155471732261526491 \\
-0.00073663742886719859 \\
-0.00087436281264190545 \\
0.00000010662872093383 \\
0.00000043891915441287 \\
0.00000015019093414260 \\
-0.00000000000221968508 \\
-0.00000000002875142096 \\
-0.00000000002809420215 \\
-0.00000000000626966800
\end{array}\right)
$$


Degree 3 with 10 terms (21 Points)

$$
\left(\begin{array}{l}
a_{0} \\
a_{1} \\
a_{2} \\
a_{3} \\
a_{4} \\
a_{5} \\
a_{6} \\
a_{7} \\
a_{8} \\
a_{9}
\end{array}\right)=\left(\begin{array}{c}
2.43847691383301074294 \\
-0.00047806506299681554 \\
-0.00068328373815848417 \\
0.00000007082027279844 \\
0.00000036320471120925 \\
0.00000012614935986116 \\
-0.00000000000277662777 \\
-0.00000000001995171264 \\
-0.00000000002572534018 \\
-0.00000000000536407133
\end{array}\right)
$$

Applying the fifth-degree with 23 terms polynomial surface given in equation (4), 23 points, 22 points except for point SLK01 and 21 points except for points SLK01 and UU03 given in table 1 were also used. The model parameters of the various point numbers using the fifth-

Degree 5 with 10 terms (23 Points)

$\left(\begin{array}{l}a_{o} \\ a_{1} \\ a_{2} \\ a_{3} \\ a_{4} \\ a_{5} \\ a_{6} \\ a_{7} \\ a_{8} \\ a_{9} \\ a_{10} \\ a_{11} \\ a_{12} \\ a_{13} \\ a_{14} \\ a_{15} \\ a_{16} \\ a_{17} \\ a_{18} \\ a_{19} \\ a_{20}\end{array}\right)=\left(\begin{array}{c}5.21254998397845812746 \\ -0.00360955700267510031 \\ -0.00565293996309406920 \\ 0.00000374631209072872 \\ 0.00000136757128228173 \\ 0.00000000000015298970 \\ -0.00000000128629548938 \\ -0.00000000098018688082 \\ -0.00000000012478321152 \\ -0.00000000052917832359 \\ 0.00000000000021748849 \\ -0.00000000000000003740 \\ 0.00000000000000001552 \\ 0.00000000000011102756 \\ -0.00000000000002536577 \\ 0.00000000000004442516 \\ -0.00000000000000000077 \\ 0.000000000000000000934 \\ -0.00000000000000000108\end{array}\right)$

Degree 3 with 10 terms (11 Points)

$$
\left(\begin{array}{l}
a_{0} \\
a_{1} \\
a_{2} \\
a_{3} \\
a_{4} \\
a_{5} \\
a_{6} \\
a_{7} \\
a_{8} \\
a_{9}
\end{array}\right)=\left(\begin{array}{c}
2.84134210525036567641 \\
-0.00039174295957339386 \\
-0.00122024751385652224 \\
-0.00000005315852447551 \\
0.00000085679211426198 \\
-0.00000004681893390540 \\
0.00000000001798607866 \\
-0.00000000008091676863 \\
-0.00000000001947174558 \\
0.00000000000923505057
\end{array}\right)
$$

degree polynomial surface were as well computed with least squares technique as well as equation (6). The computed model parameters for 23,22 and 21 points using the fifth degree polynomial surface are respectively:

Degree 5 with 10 terms (22 Points)

$\left(\begin{array}{l}a_{0} \\ a_{1} \\ a_{2} \\ a_{3} \\ a_{4} \\ a_{5} \\ a_{6} \\ a_{7} \\ a_{8} \\ a_{9} \\ a_{10} \\ a_{11} \\ a_{12} \\ a_{13} \\ a_{14} \\ a_{15} \\ a_{16} \\ a_{17} \\ a_{18} \\ a_{19} \\ a_{20}\end{array}\right)=\left(\begin{array}{c}7.30603629707767289898 \\ -0.01241421010635155914 \\ -0.00921069831052644470 \\ 0.00000770915077418606 \\ -0.00001178307394182408 \\ -0.00000000000001862531 \\ -0.0000000000496385593976 \\ -0.00000000000043701290 \\ 0.00000000000000007432 \\ -0.00000000000000007645 \\ 0.00000000000176869774 \\ 0.00000000000077479601 \\ 0.00000000000009718472 \\ 0.00000000000000000336 \\ -0.00000000000000010210 \\ -0000000000000000000000000077\end{array}\right)$


Degree 5 with 10 terms (22 Points)

$\left(\begin{array}{l}a_{o} \\ a_{1} \\ a_{2} \\ a_{3} \\ a_{4} \\ a_{5} \\ a_{6} \\ a_{7} \\ a_{8} \\ a_{9} \\ a_{10} \\ a_{11} \\ a_{12} \\ a_{13} \\ a_{14} \\ a_{15} \\ a_{16} \\ a_{17} \\ a_{18} \\ a_{19} \\ a_{20}\end{array}\right)=\left(\begin{array}{c}4.08962429231355884825 \\ -0.00657653579427171073 \\ -0.00603156890006715885 \\ 0.00000564857097738800 \\ 0.00000971366697831134 \\ 0.00000637583787244764 \\ -0.00000000000097728351 \\ 0.00000000888273254851 \\ -0.00000001233708878443 \\ -0.00000000619639899917 \\ -0.00000000140699968469 \\ -0.00000000000127814393 \\ 0.00000000000000024780 \\ -0.00000000000000014322 \\ 0.00000000000324539422 \\ 0.00000000000111113695 \\ 0.00000000000005833078 \\ -0.00000000000000000360 \\ -0.00000000000000018917 \\ 0.00000000000000000193\end{array}\right)$

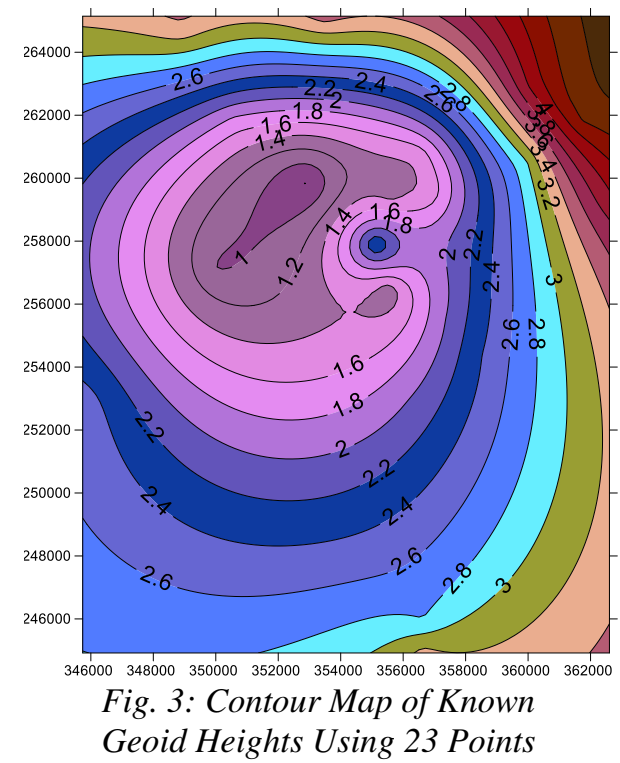

The reliability, as well as the accuracy of the two polynomial geometric surfaces using the various point numbers, were computed by finding the differences between the models' geoid heights of the points and their corresponding known (gravimetric) geoid heights. The computed differences and the total number of points for each case were used to compute the Root Mean Square Error, RMSE of the model using equation (8).

The contour and surface maps of the models and the known, as well as the gravimetric geoid heights of the points at various measurement point numbers, were plotted with surfer 11 to present their shape graphically.

\section{RESULTS PRESENTATION AND ANALYSIS}

Figures 3 and 4 respectively present the contour and surface maps of the third-degree model using 23 observation points. Also, figures 5 and 6 respectively show the contour and surface maps of the known geoid heights of the 23 points. This was done to present graphically and compare the shapes of the model and the known geoid heights of the points to determine the resemblance as well as the variations between the model and the known geoid heights of the points. It can be respectively seen from figures 3 and 5 and figures 4 and 6 that the contour and the surface maps of the third-degree model and the known geoid heights of the points are not identical which implies that the variations between the third degree model geoid heights and the known geoid heights of the points are considerably large. Thus, using 23 points which is far larger than the third-degree surface 10 terms, the accuracy of the model is very low.

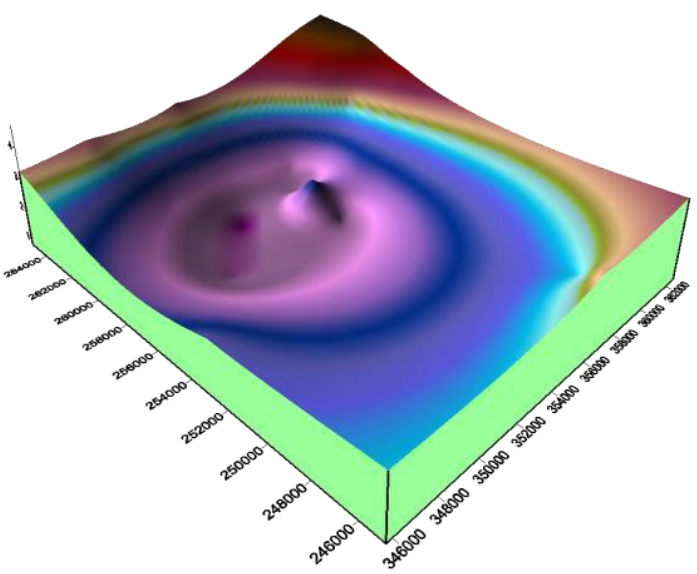

Fig. 4: Surface Map of Known Geoid Heights Using 23 Points 


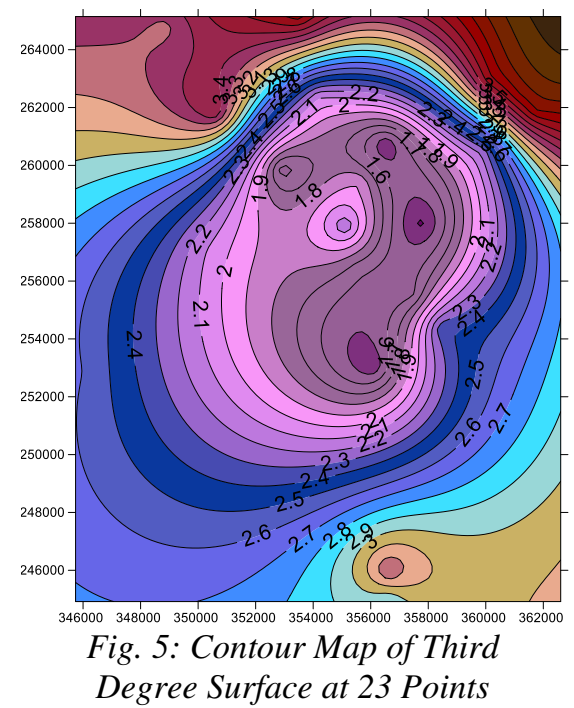

Figures 7 and 8 respectively present the contour and surface maps of the third-degree model using 22 observation points. Also, figures 9 and 10 respectively show the contour and surface maps of the known geoid heights of the 22 points. This was also done to present graphically and compare the shapes of the model and the known geoid heights of the points to determine the resemblance as well as the variations between the model and the known geoid heights of the points. It can be

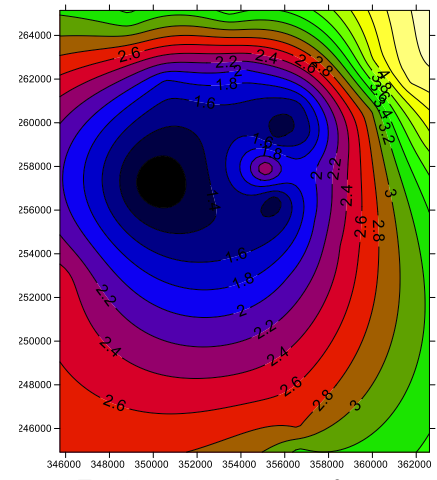

Fig. 7: Contour Map of Known Geoid Heights Using 22 Points

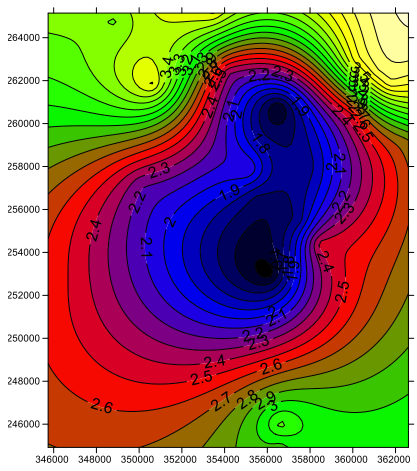

Fig. 9: Contour Map of Third Degree Surface at 22 Points

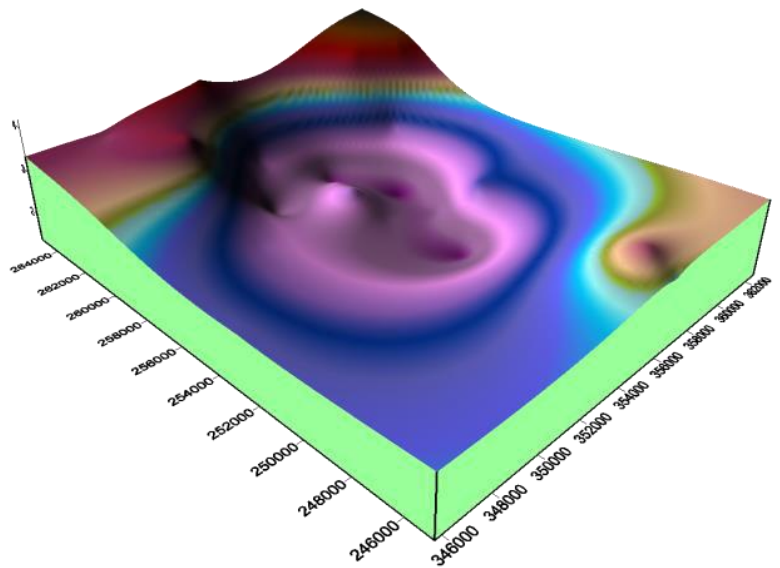

Fig. 6: Surface Map of Third Degree Model at 23 Point

respectively seen from figures 7 and 9 and figures 8 and 10 that the contour and the surface maps of the thirddegree model and the known geoid heights of the points are not identical which also implies that the variations between the third degree model geoid heights and the known geoid heights of the points are very much large. Thus, using 22 points which is also far larger than the third-degree surface 10 terms, the accuracy of the model is also very low.

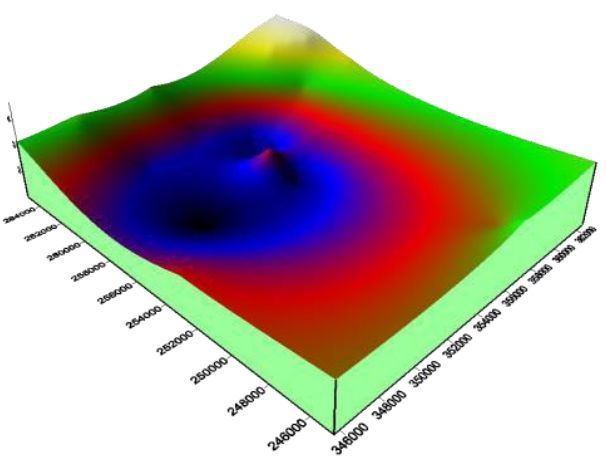

Fig. 8: Surface Map of Known Geoid Heights Using 22 Points

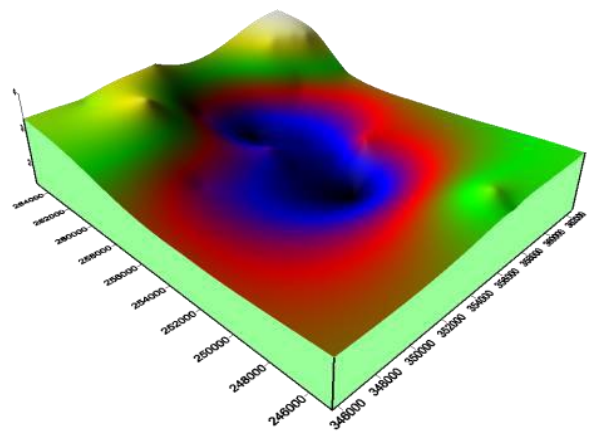

Fig. 10: Surface Map of Third Degree Model at 22 Points 
Again, figures 11 and 12 respectively show the contour and surface maps of the third-degree model using 21 observation points. Also, figures 13 and 14 respectively present the contour and surface maps of the known geoid heights of the 21 points. This was as well done to present graphically and compare the shapes of the model and the known geoid heights of the points to determine the resemblance as well as the differences between the model and the known geoid heights of the points. It can be

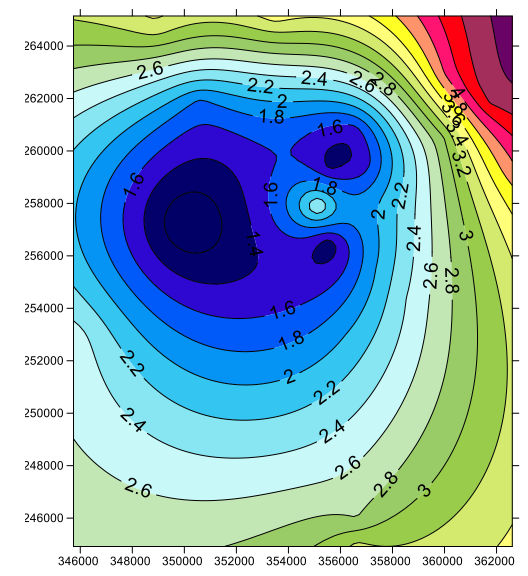

Fig. 11: Contour Map of Known

Geoid Heights Using 21 Points

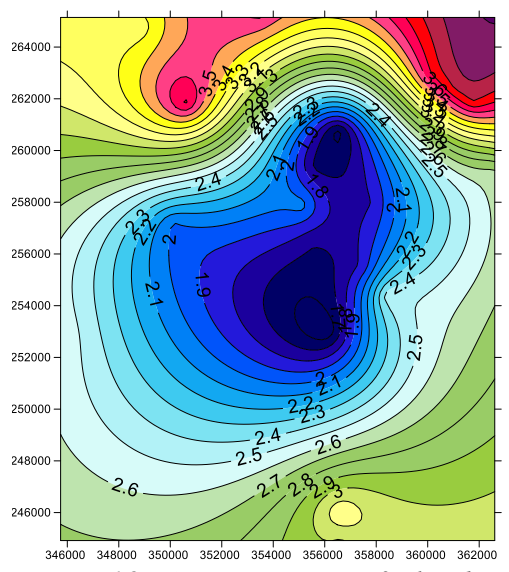

Fig. 13: Contour Map of Third

Degree Surface at 21 Points

Figures 15 and 16 respectively present the contour and surface maps of the third-degree model using 11 observation points. Also, figures 17 and 18 respectively show the contour and surface maps of the known geoid heights of the 11 points. This was as also done to present graphically and compare the shapes of the model and the known geoid heights of the points to determine the resemblance as well as the variations between the model and the known geoid heights of the points. It can as well be respectively seen from figures 15 and 17 and figures 16 and 18 that the contour and the surface maps of the respectively seen from figures 11 and 13 and figures 12 and 14 that the contour and the surface maps of the thirddegree model and the known geoid heights of the points are not identical which implies that the differences between the third degree model geoid heights and the known geoid heights of the points are greatly large. Thus, using 21 points which are as well larger than the thirddegree surface 10 terms, the accuracy of the model is well very low.

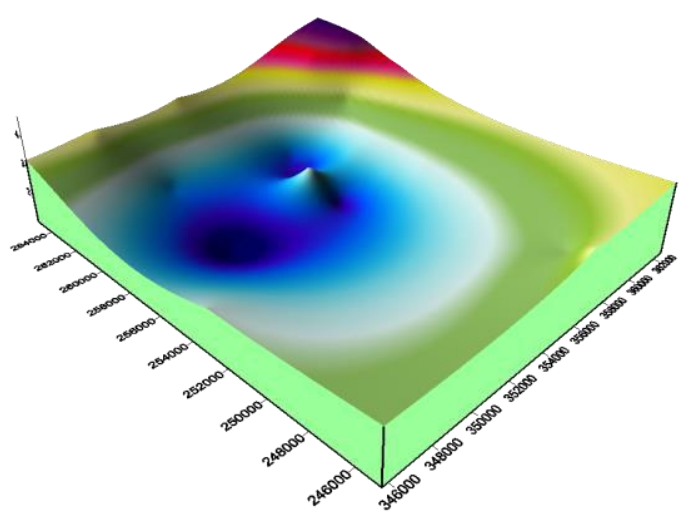

Fig. 12: Surface Map of Known Geoid Heights Using 21 Points

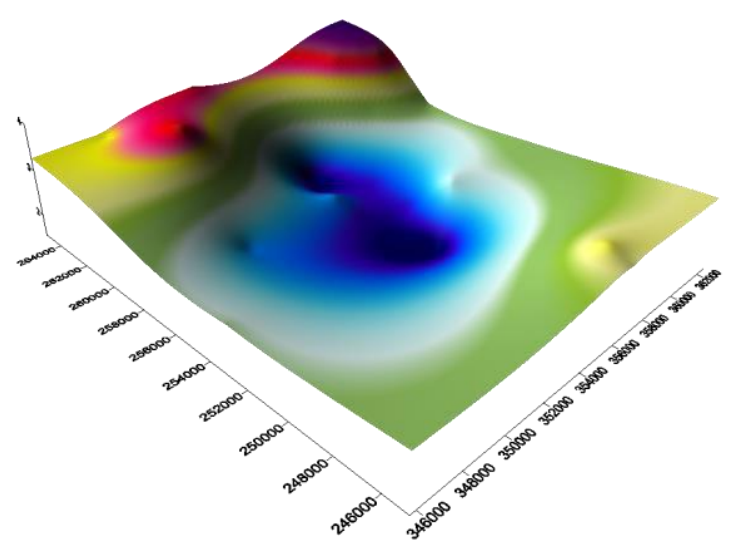

Fig. 14: Surface Map of Third Degree Model at 21 Points

third-degree model and the known geoid heights of the points are identical which implies that the variations between the third degree model geoid heights and the known geoid heights of the points are very small. Thus, using 11 points which is very close to the third-degree surface 10 terms, the accuracy of the model is very high. This also implies that the accuracy of the local geometric geoid model is highest when the number of points used is either almost or equal to the number of polynomial geometric model terms. 


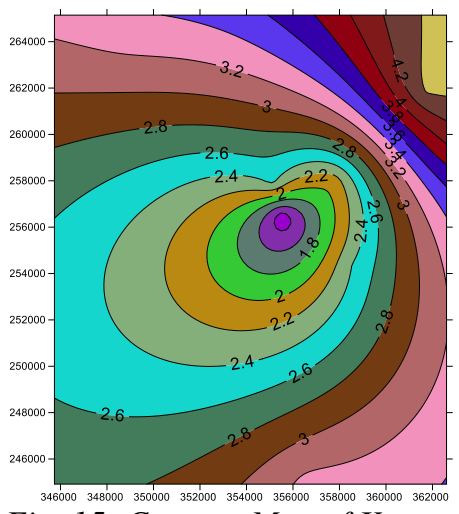

Fig. 15: Contour Map of Known Geoid Heights Using 11 Points

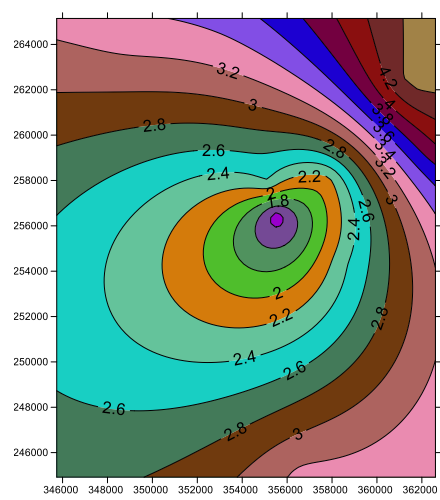

Fig. 17: Contour Map of Third

Degree Surface at 11 Points

Also, figures 19 and 20 respectively present the contour and surface maps of the fifth-degree model using 23 observation points. Again, figures 21 and 22 respectively show the contour and surface maps of the known geoid heights of the 23 points. This was as well done to present graphically and compare the shapes of the model and the known geoid heights of the points to determine the resemblance as well as the variations between the model and the known geoid heights of the points. It can also be respectively seen from figures 19 and 21 and figures 20 and 22 that the contour and the surface maps of the fifth-

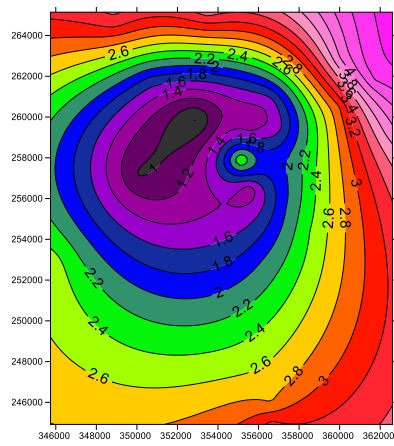

Fig. 19: Contour Map of Known

Geoid Heights Using 23 Points

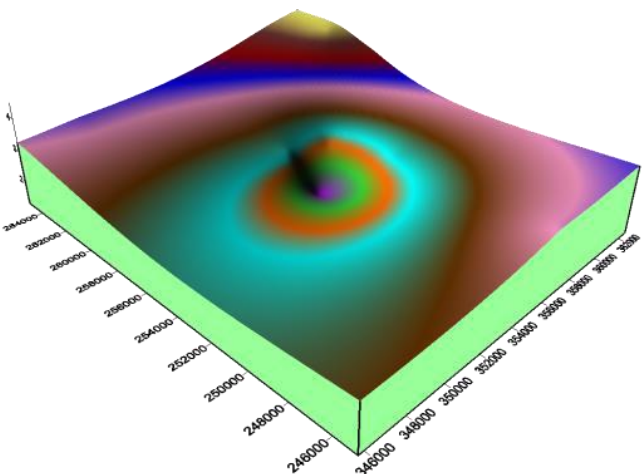

Fig. 16: Surface Map of Known Geoid Heights Using 11 Points

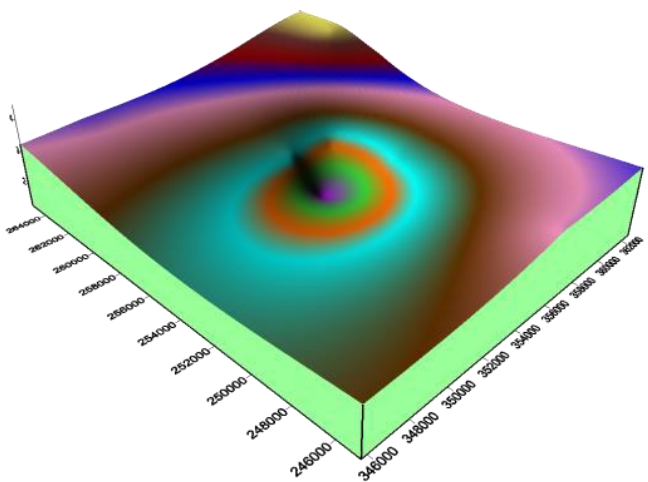

Fig. 18: Surface Map of Third Degree Model at 11 Points

degree model and the known geoid heights of the points are approximately identical which implies that the variations between the fifth-degree model geoid heights and the known geoid heights of the points are small. That is, using 23 points which is close to the fifth-degree surface 21 terms, the accuracy of the model is slightly higher. This also means that the accuracy of the local geometric geoid model increases as the number of measurement points approximates the number of geometric model terms.

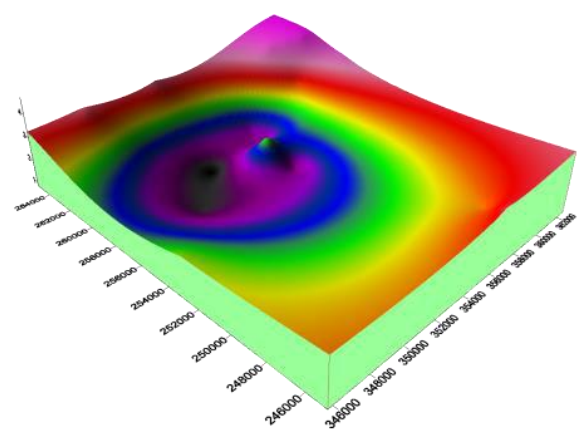

Fig. 20: Surface Map of Known Geoid Heights Using 23 Points 


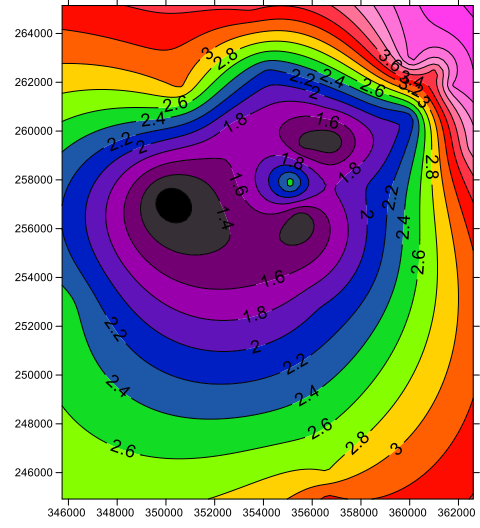

Fig. 21: Contour Map of Fifth

Degree Surface at 23 Points

Besides, figures 23 and 24 respectively present the contour and surface maps of the fifth-degree model using 22 observation points. Also, figures 25 and 26 respectively show the contour and surface maps of the known geoid heights of the 22 points. This was also done to present graphically and compare the shapes of the model and the known geoid heights of the points to determine the resemblance as well as the differences between the model and the known geoid heights of the points. It can also be correspondingly seen from figures 23 and 25 and figures 24 and 26 that the contour and the

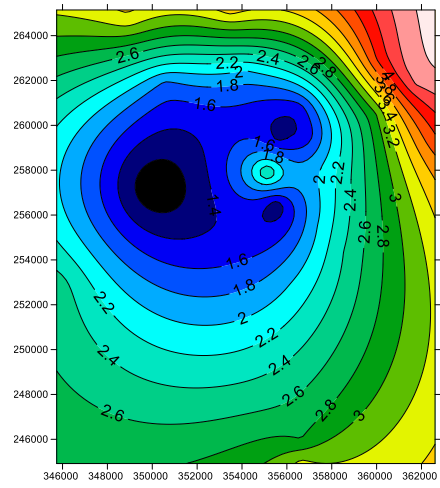

Fig. 23: Contour Map of Known Geoid Heights Using 22 Points

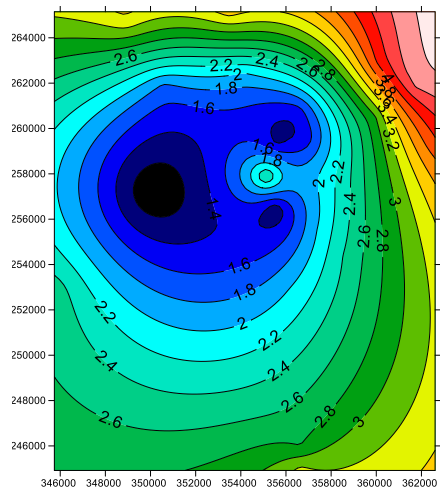

Fig. 25: Contour Map of Fifth Degree Surface at 22 Points

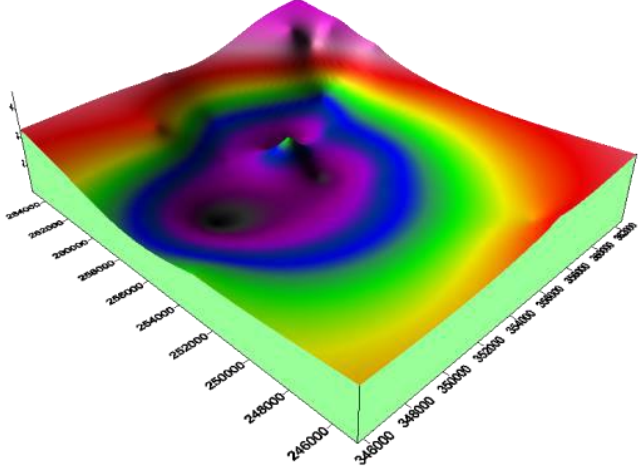

Fig. 22: Surface Map of Fifth Degree Model at 23 Points

surface maps of the fifth-degree model and the known geoid heights of the points are very much identical which implies that the variations between the fifth degree model geoid heights and the known geoid heights of the points are truly small. That is to say, using 22 points which is very close to the fifth-degree surface 21 terms, the accuracy of the model is very high. This also implies that the accuracy of the local geometric geoid model tends to the highest as the number of measurement points is closest to the number of geometric model terms.

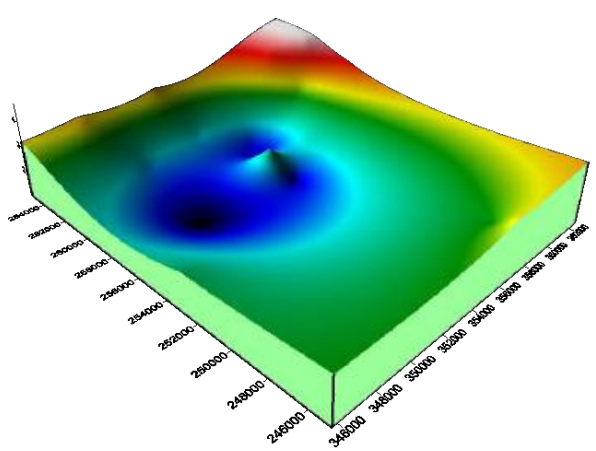

Fig. 24: Surface Map of Known Geoid Heights Using 22 Points

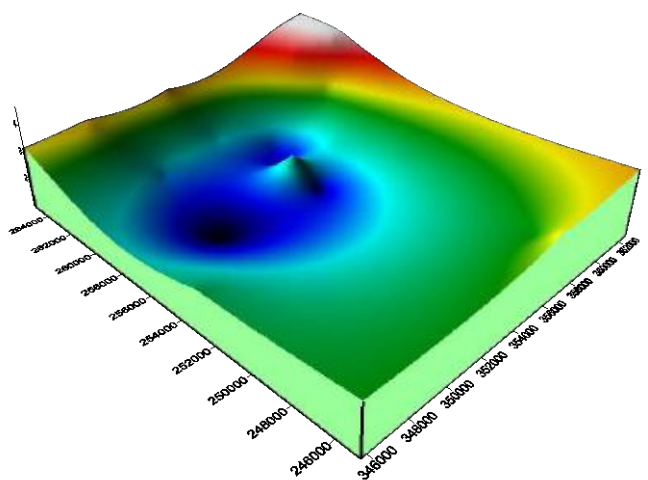

Fig. 26: Surface Map of Fifth Degree Model at 22 Points 
As well, figures 27 and 28 respectively present the contour and surface maps of the fifth-degree model using 21 observation points. Also, figures 29 and 30 respectively show the contour and surface maps of the known geoid heights of the 21 points. This was over again done to present graphically and compare the shapes of the model and the known geoid heights of the points to determine the resemblance as well as the variations between the model and the known geoid heights of the points. It can again be respectively seen from figures 27 and 29 and figures 28 and 30 that the contour and the

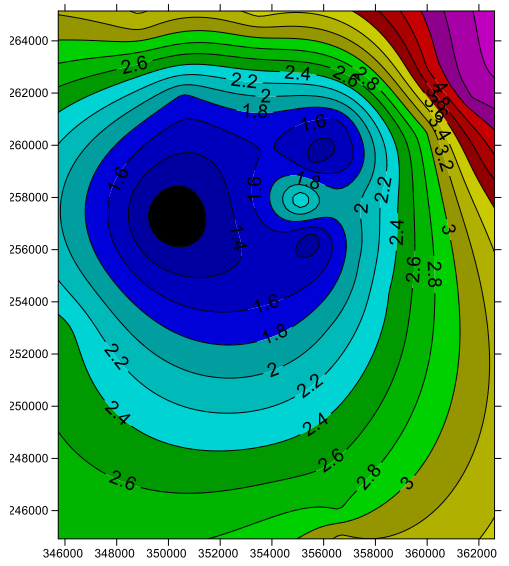

Fig. 27: Contour Map of Known Geoid Heights Using 21 Points

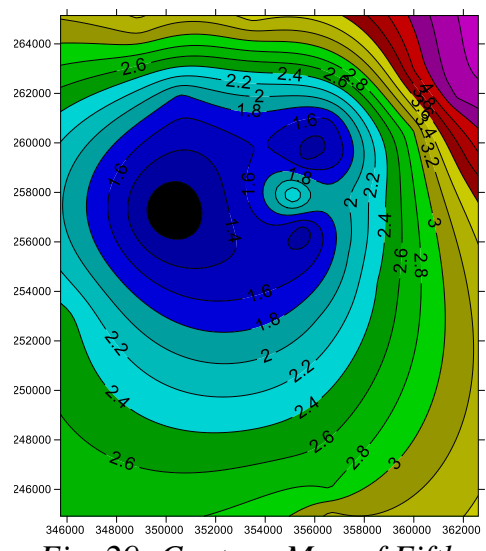

Fig. 29: Contour Map of Fifth

Degree Surface at 21 Points

Table 2 and figure 31 present the accuracy of the thirddegree model at various measurement point numbers. This was done to compare the computed accuracy of the third-degree polynomial surface at various measurement point numbers. The smaller the computed Root Mean Square Error, RMSE, the better the accuracy of the model. It can be seen from table 2 and figure 31 that the accuracy of the third-degree geometric model at 23, 22, 21 and 11 measurement points are correspondingly surface maps of the fifth-degree model and the known geoid heights of the points are extremely identical which implies that the variations between the fifth-degree model geoid heights and the known geoid heights of the points are extremely small. Therefore, using 21 points which is equal to the fifth-degree geometric model 21 terms, the accuracy of the model is highest. This also shows that the accuracy of the local geometric geoid model is highest when the number of measurement points is equal to the number of geometric geoid model terms.

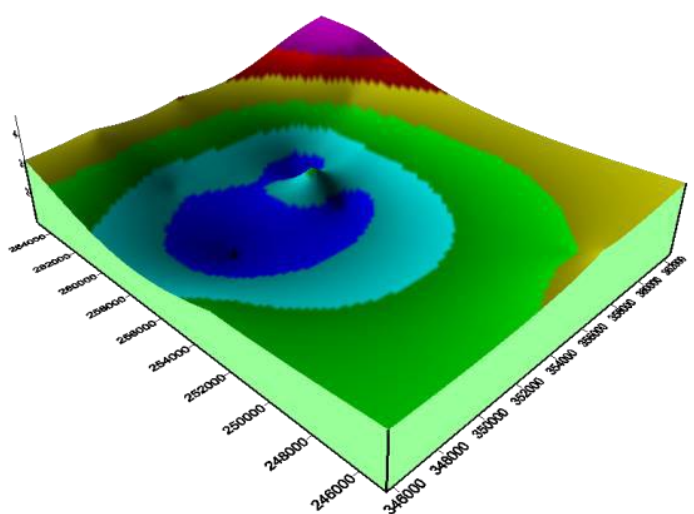

Fig. 28: Surface Map of Known Geoid Heights Using 21 Points

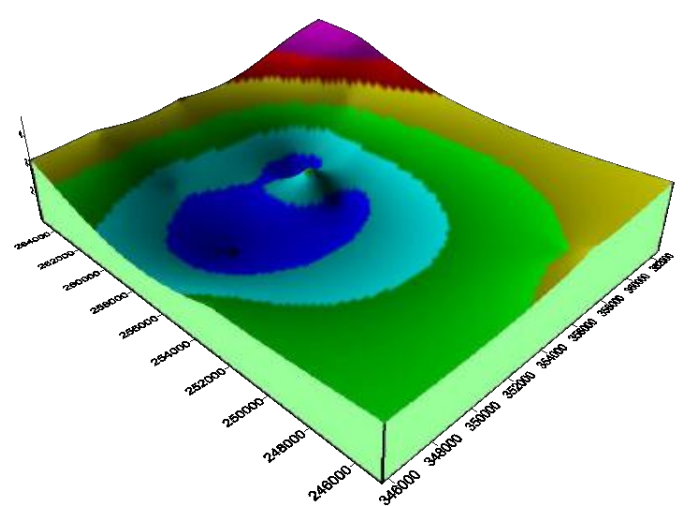

Fig. 30: Surface Map of Fifth Degree Model at 21 Points

$0.632 \mathrm{~m}, 0.6358 \mathrm{~m}, 0.6358 \mathrm{~m}$ and $0.034 \mathrm{~m}$. This means that the accuracy of the model is highest at 11 measurement points. This is as the number of points used (11) is very close to the number of the third-degree geometric model terms (10). This again, implies that the accuracy of the geometric geoid model tends to the highest as the number of measurement points approximates the number of the model terms. 
Table 2: Accuracy of the Third Degree Model at Various Measurement Point Numbers

\begin{tabular}{|l|c|c|c|c|}
\hline \multicolumn{5}{|c|}{$\mathbf{3}^{\text {rd }}$ Degres-10 Terms Geoid Surface } \\
\hline & 23 Points & 22 Points & 21 Points & 11 Points \\
\hline RMSE (m) & 0.632 & 0.6358 & 0.6358 & 0.034 \\
\hline
\end{tabular}

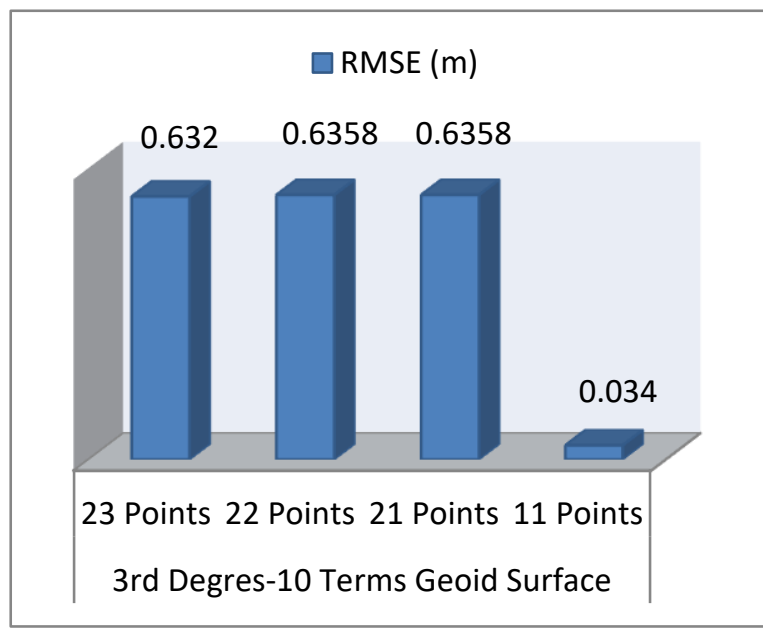

Fig. 31:Plot of Accuracy of the Third Degree Model at Various Measurement Point Numbers

Again, table 3 and figure 32 present the accuracy of the fifth-degree model at various measurement point numbers. This was as well done to compare the obtained accuracy of the fifth-degree polynomial geoid model at various measurement point numbers. The smaller the computed RMSE, the better the accuracy of the model. It can be seen from table 3 and figure 32 that the accuracy of the fifth-degree geometric model at 23, 22 and 21 measurement points are respectively $0.4333 \mathrm{~m}, 0.0046 \mathrm{~m}$ and $0.0003 \mathrm{~m}$. This means that the accuracy of the model is highest, less than $1 \mathrm{~mm}$ at 21 measurement points. Also, at 22 observation points, the accuracy of the model is within $5 \mathrm{~mm}$. This once more implies that the accuracy of the polynomial geometric geoid model tends to the highest as the number of measurement points approximates the number of the model terms and in a unique solution, when the number of observation points is equal to the number of the polynomial geometric model terms, the model accuracy is highest.

Table 3: Accuracy of the Fifth Degree Model at Various Measurement Point Numbers

\begin{tabular}{|c|c|c|c|}
\hline \multicolumn{4}{|c|}{$5^{\text {th }}$ Degres-21 Terms Geoid Surface } \\
\hline & 23 Points & 22 Points & 21 Points \\
\hline RMSE (m) & 0.4333 & 0.0046 & 0.0003 \\
\hline
\end{tabular}

www.ijeab.com

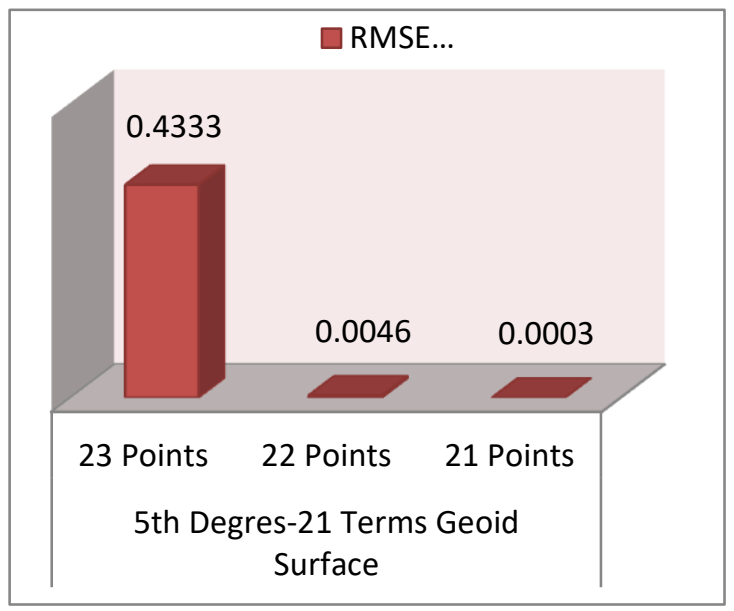

Fig. 32: Plot of Accuracy of the Third Degree Model at Various Measurement Point Numbers

IV. CONCLUSION AND RECOMMENDATIONS

1. This paper has determined the relationship between polynomial geometric geoid surface terms and observation points number and effect in the accuracy of geometric geoid models.

2. The paper has presented that the accuracy of the geometric geoid model tends to the highest as the number of measurement points approximates the number of the model terms.

3. The paper has also presented that the accuracy of the polynomial geometric geoid model is highest when the number of observation points is equal to the number of the polynomial geometric model terms

4. The obtained results have shown that the least squares model for fitting polynomial geometric surfaces to geoid heights should not just be the observation equal to the estimate but the residual should be considered as it can be used as a check. This is for the reason that the residual obtained from the difference between the estimate and the observation is equal to the difference between the model geoid height and its corresponding known geoid height.

5. The paper has also recommended that the geometric method of local geoid model determination should be strictly applied in small areas. Where the method will be applied in considerable large areas, having considered the variation of the geoid heights, higher degrees polynomial geometric surfaces with larger numbers of terms approximating the number of observation points should be applied. This will enable the proper fit of the polynomial surface to the known geoid heights, as well as high accuracy to be obtained. 


\section{REFERENCES}

[1] Erol, B. and Celik, R. N. (2004): Precise Local Geoid Determination to Make GPS Technique More Effective in Practical Applications of Geodesy. FIG Working Week, Athens, Greece.

[2] Eteje S. O., Oduyebo O. F. and Ono M. N. (2019): Derivation of Theoretical Gravity Model on the Clarke 1880 Ellipsoid for Practical Local Geoid Model Determination. Scientific Research Journal (SCIRJ), Vol. 7, No 2, pp 12-19. DOI: 10.31364/SCIRJ/v7.i2.2019.P0219612.

[3] Eteje, S. O. and Oduyebo, F. O. (2018): Local Geometric Geoid Models Parameters and Accuracy Determination Using Least Squares Technique. International Journal of Innovative Research and Development (IJIRD), Vol. 7, No 7, pp 251-257. DOI: $10.24940 / \mathrm{ijird} / 2018 / \mathrm{v} 7 / \mathrm{i} 7 / \mathrm{JUL} 18098$.

[4] Eteje, S. O., Oduyebo O. F. and Olulade S. A. (2018): Procedure for the Determination of Local Gravimetric-Geometric Geoid Model. International Journal of Advances in Scientific Research and Engineering (IJASRE), Vol. 4, No. 8, pp 206-214. DOI: 10.31695/IJASRE.2018.32858.

[5] Eteje, S. O., Ono, M. N. And Oduyebo, O. F (2018): Practical Local Geoid Model Determination for Mean Sea Level Heights of Surveys and Stable Building Projects. IOSR Journal of Environmental Science, Toxicology and Food Technology (IOSRJESTFT), Vol. 12, No 6, PP 30-37. DOI: 10.9790/2402-1206013037.

[6] Featherstone, W. E. and Olliver, J. G. (1997): A Method to Validate Gravimetric-Geoid Computation Software Based on Stokes's Integral Formula. Journal of Geodesy (1997) Vol. 71, Pp 571-576.

[7] Kao, S., Ning, F., Chen, C. and Chen, C. (2017): Using Particle Swarm Optimization to Establish a
Local Geometric Geoid Model. Boletim de Ciências Geodésicas, Vol. 23, No. 2, pp. 327-337.

[8] Kirici, U. and Sisman, Y. (2017): The Comparison of the Adjustment Methods In Geoid Determination Method. FIG Working Week, Helsinki, Finland.

[9] Mishima, K. and Endo, K. (2002): The Method of the Design for Survey Network by Q Matrices. Proceedings of the 7th International Workshop on Accelerator Alignment, Spring.

[10] Oluyori, P. D., Ono, M. N. and Eteje, S. O. (2018): Comparison of Two Polynomial Geoid Models of GNSS/Levelling Geoid Development for Orthometric Heights in FCT, Abuja. International Journal of Engineering Research and Advanced Technology (IJERAT), Vol. 4, No. 10, pp 1-9. DOI: 10.31695/IJERAT.2018.3330.

[11] Oluyori, P. D., Ono, M. N. and Eteje, S. O. (2018): Computations of Geoid Undulation from Comparison of GNSS/Levelling with EGM 2008 for Geodetic Applications. International Journal of Scientific and Research Publications (IJSRP), Vol. 8, No. 10, pp 235-241. DOI: 10.29322/IJSRP.8.10.2018.p8230.

[12] Ono, M. N., Agbo, J. A., Ijioma, D. I. and Chubado, M. (2014): Establishment of Baseline Data for Monitoring of Deformation of Murtala Mohammed Bridge (MMB) Lokoja Kogi State, Using GPS. International Journal of Science and Technology (IJST), Vol. 4 No.5, pp 86-92.

[13] Ono, M. N., Eteje, S. O. and Oduyebo, F. O. (2018): Comparative Analysis of DGPS and Total Station Accuracies for Static Deformation Monitoring of Engineering Structures. IOSR Journal of Environmental Science, Toxicology and Food Technology (IOSR-JESTFT), Vol. 12, No. 6, PP 1929. DOI: 10.9790/2402-1206011929. 